\title{
Awareness and Management of Bleeding Disorder Amongst Dental Practitioners in Enugu, South East, Nigeria
}

\author{
Okoye HC ${ }^{1}$, Efobi CC ${ }^{2}$, Korubo $\mathrm{KI}^{3}$ and Chukwuneke FN ${ }^{4 *}$ \\ ${ }^{1}$ Department of Hematology and Immunology, University of Nigeria, Nigeria \\ ${ }^{2}$ Deptartment of Hematology and Blood Transfusion, Nnamdi Azikiwe University Nnewi Campus, Nigeria \\ ${ }^{3}$ Department of Hematology and Blood Transfusion, University of Port Harcourt, Nigeria \\ ${ }^{4}$ Department of Oral and Maxillofacial Surgery, University of Nigeria, Nigeria
}

Submission: April 16, 2021; Published: April 27, 2021

*Corresponding author: Chukwuneke FN, Department of Oral and Maxillofacial surgery, Faculty of Dentistry , College of Medicine, University of Nigeria Ituku-Ozalla Campus, Enugu Nigeria

\section{Abstract}

Background: Bleeding disorder in dental practice is generally low but could be very devastating when it occurs. This can be averted with timely recognition of the features through proper clinical assessment and initiating early treatment to avoid disastrous consequences.

Objectives: The aim of this study was to evaluate the awareness of bleeding disorders among dental practitioners in everyday practice, and their ability to recognize and manage such cases.

Methods: We carried out a descriptive cross-sectional study using a 12 -stem pre-tested questionnaire. A total of 47 dental practitioners were self-interviewed over a period of 6 months. The responses obtained were converted to relative values for generation of statistics using window SPSS $®$ version 21.

Results: Of the 47 respondents, 46 (97.8\%) were aware that bleeding disorders exist and majority (95.7\%) agreed that some of their patients may have bleeding disorders. Clinical history often requested include family history of bleeding $20(42.6 \%)$, significant bleeding after surgery or following extraction $19(40.4 \%)$ and drug history $19(40.4 \%)$. Most practitioners $(34 ; 72.1 \%)$ always carry out gum examinations for bleeding disorder while $28(60.9 \%)$ always examined for gum hypertrophy. More than half of the respondents $(\mathrm{n}=25,54.3 \%)$ always request for a full blood count test. Fourteen practitioners (29.8\%) have never requested for Prothrombin Time. Majority, 37(80.4\%) manage patients with mild bleeding disorder but $43(91.1 \%)$ would refer severe cases. After dental procedures, most practitioners $44(93.3 \%)$ look for delayed bleeding and 39 (92.9\%) had encountered unexpected bleeding in their practice.

Conclusion: Although most dental practitioners are aware of bleeding disorders, there is a need to identify susceptible cases and be properly guided with sufficient knowledge and skills in managing such. They should therefore be encouraged to thoroughly screen their patients prior to dental procedures in order to avoid unexpected postoperative bleeding challenges.

Keywords: Bleeding disorder; Awareness; Management; Dental practitioners

Abbreviations: BD: Bleeding Disorders; PT: Prothrombin Time; APTT: Activated Partial Thromboplastin Time

\section{Introduction}

Bleeding disorders (BD) are either acquired or congenital and may manifest for the first time during a dental procedure or some days later, therefore posing a haemostatic challenge especially in non-severe forms [1]. One of the reasons for a visit to the dental clinic may be a bleeding disorder in patients presenting with bleeding gums [2], although there are other causes of gum bleeding unrelated to bleeding disorders. Alteration in the components of haemostasis including the vessel wall, platelets, coagulation and fibrinolytic proteins result in BD [3,4]. Haemostatic defects secondary to an underlying disease or drugs are more frequent in clinical practice while the inherited causes of bleeding disorders are relatively rare [5]. Bleeding in the oral cavity may be as a result of local causes such as poor oral hygiene, infection or local trauma. It may also be as a result of a systemic conditions as seen in bleeding disorders [1], drugs, malnutrition, malignancy and hormonal changes [6]. 
Bleeders may be recognized through a detailed history, careful physical examination and appropriate laboratory investigations [7]. Although the incidence of bleeding disorder is generally low, encountering a bleeder unexpectedly in clinical practice can be devastating with serious consequences. This may be averted with proper assessment and detailed laboratory investigations for patients prior to any invasive dental procedure. Prompt recognition of tell-tale signs of bleeding disorder in a patient is an essential preliminary procedure to an uneventful and effective treatment. As we do not at present know of any study on dental practitioners preclinical assessment and management procedures for bleeding disorder amongst dental patients prior to invasive treatment, we undertook a descriptive cross-sectional study to evaluate the awareness of bleeding disorders among dental practitioners in their daily practices, their ability to recognize and assess susceptible cases and their management approach.

\section{Methodology}

This is a descriptive cross-sectional questionnaire-based survey carried out in the South-Eastern region of Nigeria over a period of 6 months (September 2016 to February 2017). A 12stem pre-tested questionnaire was used. Questionnaires were distributed to the dental practitioners during some academic gathering while others responded in their offices. The demographic data of participants was obtained as well as, their level of awareness of bleeding disorders in practice (items 1-6), medical history obtained from patients (item 7), physical examinations elicited for (item 8), investigations requested (9) and line of management (items 10-12). - Appendix 1. The responses obtained were converted to relative values for generation of statistics and analyzed with the statistical package for social sciences (SPSS) ${ }^{\circledR}$ version 21.0. (IBM corp. Armonk, NY, USA). The results were expressed as frequencies and presented in tables.

\section{Results}

There were 60 questionnaires distributed, while 47 dental practitioners participated in the survey giving a $78.3 \%$ response rate. Of the 47 respondents, 28 (59.6\%) were males while 15 (31.9\%) were females giving a male-to-female ratio of 1.8:1 with no indication of sex in four respondents. The age distribution of the participants were 21-30 years ( $n=9,19.1 \%) ; 31-40$ years $(\mathrm{n}=22,46.8 \%) ; 41-50$ years $(\mathrm{n}=13,27.7 \%), 51-60$ years $(\mathrm{n}=2$, $4.3 \%)$ and $>60$ years $(n=1,2.1 \%)$. Majority of the respondents were consultants $(n=13,29.5 \%)$ followed by senior registrars with medical officers ( $n=9,20.5 \%$ each); house officers $(n=1=7$, $15.9 \%)$ and registrars $(n=6,13.6 \%)$. The number of years of practice for the respondents is shown in Figure 1. The dental subspecialties included; 11 general dentistry (26.2\%), 11 Oral and maxillofacial surgery (26.2\%), 8 preventive dentistry (19\%), 4 oral pathology (9.5\%), 3 child dental health $(7.1 \%), 2$ periodontology (4.8\%)- while community dentistry, conservative dentistry and child dental health each had 1 participant (2.4\% each). Most of the dental practitioners $(n=46,97.9 \%)$ were aware of bleeding disorders and 45 (95.7\%) agreed that some of their patients may have bleeding disorders. Table 1 showed the responses for history taken from patients prior to dental procedures while Table 2 showed the physical examination performed by the respondents on their patients prior to dental procedures.

Table 1: History Obtained from Patients.

\begin{tabular}{|c|c|c|c|c|c|}
\hline & Always & Most Times & Sometimes & Occasnally/ Seldomly & Never \\
\hline History Obtained from Patients & Number (\%) & Number (\%) & Number (\%) & Number (\%) & Number $(\%)$ \\
\hline $\begin{array}{l}\text { significant or prolonged bleeding after } \\
\text { trauma or surgery }\end{array}$ & $19(40.4)$ & $7(14.9)$ & $7(14.9)$ & $11(23.4)$ & $3(6.4)$ \\
\hline spontaneous bleeding/ easy bruising & $16(34.0)$ & $7(14.9)$ & $11(23.4)$ & $12(25.5)$ & $1(2.1)$ \\
\hline nasal or oral bleeds & 7 (14.9) & $5(10.6)$ & $10(21.3)$ & $15(31.9)$ & $10(21.3)$ \\
\hline menorrhagia & $2(4.5)$ & $1(2.3)$ & $5(11.4)$ & $15(34.1)$ & $21(47.7)$ \\
\hline family $\mathrm{hx}$ of bleeding & $20(43.5)$ & $4(8.7)$ & $8(17.4)$ & $9(19.6)$ & $5(10.9)$ \\
\hline bleeding after IM or venipuncture & $9(19.1)$ & $6(12.8)$ & $12(25.5)$ & $11(23.4)$ & $9(19.1)$ \\
\hline drug history & $19(40.4)$ & $8(17.0)$ & $8(17.0)$ & $8(17.0)$ & $4(8.5)$ \\
\hline previous blood transfusion & $10(31.3)$ & $7(21.9)$ & $11(34.4)$ & $0(0.0)$ & $4(12.5)$ \\
\hline constitutional symptoms & $3(6.4)$ & $7(14.9)$ & $15(31.9)$ & $9(19.1)$ & $13(27.7)$ \\
\hline $\begin{array}{l}\text { excessive bleeding after previous } \\
\text { extraction }\end{array}$ & $19(40.4)$ & $8(17.0)$ & $5(10.6)$ & $14(29.8)$ & $1(2.1)$ \\
\hline
\end{tabular}




\section{Advances in Dentistry \& Oral Health}

Table 2: Physical Examinations Done on Patients.

\begin{tabular}{|c|c|c|c|c|c|}
\hline Pt. Examination & Always & Most Times & Sometimes & Occasnally/ Seldomly & Never \\
\hline & Number (\%) & Number (\%) & Number (\%) & Number (\%) & Number (\%) \\
\hline Petechiae, purpura, echymosis & $15(32.6)$ & $10(21.7)$ & $9(19.6)$ & $6(13.0)$ & $6(13.0)$ \\
\hline bleeding wounds & $14(30.4)$ & $13(28.3)$ & $12(26.1)$ & $4(8.7)$ & $3(6.5)$ \\
\hline evident haematoma & $6(13.6)$ & $8(18.2)$ & $18(40.9)$ & $7(15.9)$ & $5(11.4)$ \\
\hline swollen joints & $4(8.7)$ & $5(10.9)$ & $8(17.4)$ & $16(34.8)$ & $13(28.3)$ \\
\hline gum bleeds & $31(72.1)$ & $8(18.6)$ & $3(7.0)$ & $0(0.0)$ & $1(2.3)$ \\
\hline gum hypertrophy & $28(60.9)$ & $7(15.2)$ & $5(10.9)$ & $4(8.7)$ & $2(4.3)$ \\
\hline
\end{tabular}

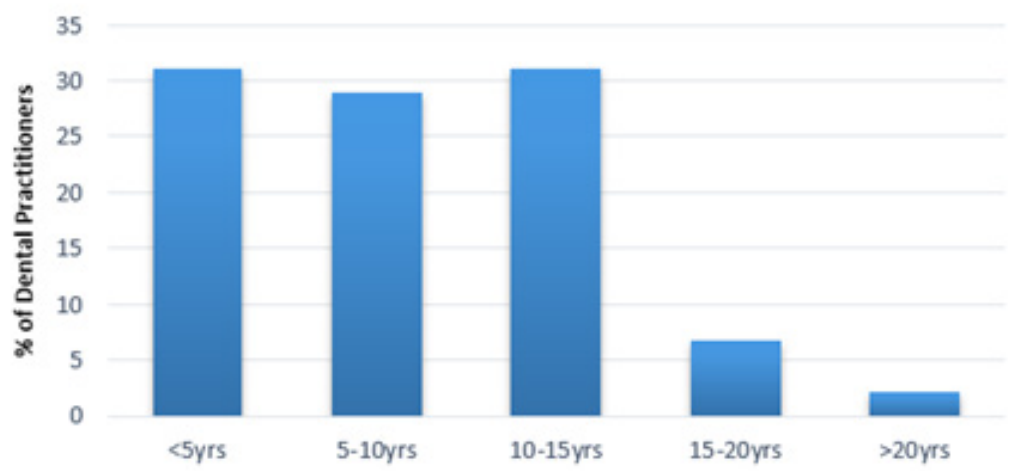

Figure 1: Number of Years of Practice.

With regards to pre-operative investigations, more than half of the respondents always order for a haematocrit $(n=26,56.5 \%)$ or full blood count ( $n=25,54.3 \%)$. About a quarter $(26.7 \%)$ never requested for a peripheral blood film report. Only 2 (4.4\%) always requested for a bleeding time while $14(31.1 \%)$ did so sometimes and a third of them $(n=15,33.3 \%)$ rarely did. Prothrombin time (PT) was always requested by only $3(6.5 \%)$ dental practitioners while 14 (30.4\%) never did. The rest did so rarely, ( $n=13,28.3 \%)$, sometimes $(n=11,23.9 \%)$ or most of the time $(n=5,10.9 \%)$. Majority of the dental practitioners ( $\mathrm{n}=2453.3 \%)$ never requested for the activated partial thromboplastin time (APTT) while only $2(4.4 \%)$ always requested for it. The rest of the practitioners requested for APTT rarely ( $n=10,22.2 \%)$, most of the time $(n=5$, $11.1 \%)$ and some of the time $(n=4,8.9 \%)$. Liver function test was never ordered for by 18 (39.1\%) of the dental practitioners, while 16 (34.8\%) did so rarely. More than a third ( $n=18,39.1 \%)$ never requested for renal function tests, while 7 (15.2\%) did and $10(21.7 \%)$ rarely. On what action to take if they encountered a patient with a bleeding disorder or at risk of bleeding, majority ( $n=37,80.4 \%$ ) said they would manage the patient with mild presentation but refer severe cases. , 10 (22.7\%) would refer the patient to the internal physicians while 41 (91.1\%) would refer to the haematologist.
The respondents were almost split in two when asked if they would cancel or defer the case with bleeding disorder or at risk of bleeding with $47.7 \%$ saying they will suspend the procedure while $52.3 \%$ decided they will go ahead with it. After dental procedures most of the dental practitioners $(n=42,93.3 \%)$ looked for delayed bleeding in their patients, $43(93.5 \%)$ were careful about using drugs which may predispose to bleeding. About 38 (84.4\%) were knowledgeable about drug-drug interactions which may predispose to post-operative bleeding in their patients. Up to 39 (92.9\%) had encountered unexpected bleeding in their practice. Measures taken to control bleeding included use of antifibrinolytic agents $(n=28,80 \%)$ and referral to a senior colleague $(n=25$, $71.4 \%)$, internal physicians $(n=10,20 \%)$ or haematologists $(n=32$, $84.2 \%)$. Other measures taken by a minority (14.9\%) included the use of vitamin K, ice cold or adrenalin-soaked gauze, surgical and blood transfusion including the use of fresh frozen plasma.

\section{Discussion}

Bleeding disorders may be inherited or acquired and are characterized by defective blood clotting. Abnormal bleeding may be due to vascular disorders, platelet disorders and defective coagulation. They may present as petechial, purpuric or echymotic haemorrhages, easy bruising, menorrhagia, epistaxis and gum 
bleeding. It is very important that dental practitioners are aware of the impact of bleeding disorders in patient management [8], as invasive dental procedures may cause uncontrollable bleeding in haemostatic challenged patients. We found that most of the dental practitioners were aware of existence of bleeding disorders as reported by similar studies $[9,10]$. Another study done at Shiraz in Iran found their dentists' knowledge of bleeding disorders to be suboptimal, therefore requiring continuing medical education [11]. Proper laboratory investigations for patients undergoing invasive dental procedures is ideal as this will aid in identification of bleeders in unsuspected cases. We noted that most dental practitioners only request for haematocrit or full blood count as pre-operative investigations, which is inadequate for detecting bleeding disorders.

Most of our dental practitioners never or rarely requested for coagulation screening tests, renal and liver function tests. In a related study, Robati et al. [11] reported poor knowledge of preoperative laboratory investigations required prior to dental procedures. This may be due to poor understanding of causes of bleeding disorders or because the financial standing of the patient is being considered With inadequate pre-operative laboratory screening, there is a good chance of missed diagnosis which could lead to severe bleeding in a previously undiagnosed patient. Contrary to our findings, Ajrish et al. [9] reported that dental practitioners in their study requested more of bleeding time and clotting time, while rarely requesting for full blood count. A few requested specifically for the platelet count. There is need to sensitize the dental practitioners on the importance of extensive laboratory investigations for patients so as to rule out BDs prior to performing invasive procedures. Management of bleeding disorders requires a multidisciplinary approach. Majority of our respondents said they would refer severe cases of $\mathrm{BD}$, with most of them sending their patients to haematologists.

This shows their awareness of the multidisciplinary approach in management of bleeding disorders. Just as we observed, Shah et al also reported that most of their dentists would prefer a specialist's opinion in such patient management [12]. Most of the dental practitioners would control bleeding using antifibrinolytic agents, while a few would use vitamin $\mathrm{K}$, ice cold (or adrenalin soaked) gauze, surgicel and blood transfusion including the use of fresh frozen plasma. This is similar to the findings by Ajrish et al. [9]. A detailed history and physical examination are essential in the diagnosis of BDs. We found that most of our respondents were not consistent with taking good history and physical examination of their patients in respect to bleeding disorder. This could lead to missed diagnosis, especially without proper laboratory investigations.

\section{Conclusion}

This study has shown that dental practitioners have good level of knowledge and awareness of bleeding disorders however, most do not always initiate laboratory investigation and proper screening of patients before dental treatment. This default attitude may lead to missed diagnosis of susceptible cases with resultant serious post-surgical bleeding complications. It is therefore necessary to increase awareness among dental surgeons through continuing medical education as well as instituting guidelines for proper history taking, physical examination and laboratory investigations while carrying out invasive dental procedures.

\section{References}

1. Van Galen KPM, Engelen ET, Mauser-Bunschoten EP, Robert JJ van Es, Schutgens REG (2015) Antifibrinolytic therapy f or preventing oral bleeding in patients with haemophilia or Von Willebrand disease undergoing minor oral surgery or dental extractions. Cochrane Data base Syst Rev (12): CD011385.

2. Rai A, Vaishali V, Naikmasur VG, Kumar A, Sattur A (2016) Aplastic anemia presenting as bleeding of gingiva: Case report and dental considerations. The Saudi Journal for Dental Research 7(1): 69-72.

3. Goswami A, Bora A, Kundu GK, Ghosh S, Goswami A (2014) Bleeding disorders in dental practice: A diagnostic overview . J Int Clin Dent Res Organ 6(2): 143-150.

4. Okoye HC, Korubo KI, Nwogoh B, Efobi CC, Ugwu NI, et al. (2018) Challenges in the management of bleeding disorders in Nigeria. Niger $J$ Clin Pract 21(4): 468-472.

5. Isreal S, Schwetz N, Boyar R, McNicol A (2006) Bleeding disorders: characterization, dental considerations and management. J Can Dent Assoc 72(9): 827.

6. Vassilopoulos P, Palcanis K (2007) Bleeding disorders and periodontology Periodontology 2000 44: 211-223.

7. Goswami A, Bora A, Kundu GK, Ghosh S, Goswami A (2014) Bleeding disorders in dental practice: A diagnostic overview. J Int Clin Dent Res Organ 6(2): 143-150.

8. Gupta A, Epstein JB, Cabay RJ (2007) Bleeding disorders of importance in dental care and related patient management 73(1):77-83.

9. Ajrish G, Sherlin HD (2017) Awareness of bleeding disorder amongst dental practitioners. J Pharm Sci \& Res 9(12): 2440-2443.

10. Saleh MR (2006) Evaluation of the knowledge and application of Isfahan dentists about coagulation tests in patients with coagulation disorders. Journal of Isfahan Dental Scchool 2(1): 59-62.

11. Robati R, Farokhi MM (2013) Evaluation of dentists' awareness of inherited bleeding disorders and anticoagulants in Shiraz. Iranian Journal of Pediatric Hematology and Oncology 3(4): 159-163.

12. Shah AH, Khalil SH, Alsharhani FA, Khan SQ, AlQthani NR, et al. (2015) Knowledge of medical and dental practitioners towards dental management of patients on anticoagulants and/or antiplatelet therapy. The Saudi Journal of Dental Research 6(2): 91- 97. 
This work is licensed under Creative Commons Attribution 4.0 License DOI: 10.19080/ADOH.2021.14.555882
Your next submission with Juniper Publishers will reach you the below assets

- Quality Editorial service

- Swift Peer Review

- Reprints availability

- E-prints Service

- Manuscript Podcast for convenient understanding

- Global attainment for your research

- Manuscript accessibility in different formats

( Pdf, E-pub, Full Text, Audio)

- Unceasing customer service

Track the below URL for one-step submission https://juniperpublishers.com/online-submission.php 